\title{
Game Analysis of Collusion between Managers And Independent Directors - Based on Government Supervision Model
}

\author{
Feng-su Yang, Xiao-rong Du, and Ma-li Ji \\ Business School, Hohai University, Nanjing, Jiangsu, China \\ yangfengsu1@163.com
}

\begin{abstract}
The paper first analyzes the motivation of the appearance of collusion between managers and independent directors. Then, based on the conspiracy theory,the paper establishes the game model on collusion between managers and independent directors under government supervision. Next, the paper analyzes all the factors contributing to the collusion from the perspective of game theory. Lastly, some suggestions are put forward about how to prevent the collusion based on game analysis. The study finds it is effective to stop the collusion by improving government supervision quality, establishing an effective penalty mechanism, perfecting independent directors' salary system and strengthening the directors' reputation incentive mechanism.

Index Terms - Managers, Independent directors, Government supervision, Collusion, Game analysis
\end{abstract}

\section{Introduction}

With "The Guidance on the Establishment of the Independent Director System in Listed Companies" published by China Securities Regulatory Commission, the independent director system was established formally. But the effectiveness of the system is not as good as expected. Independent directors and managers conspire to encroach interests of the minority shareholders due to considerations of personal economic benefits. Many scholars have explored this issue, which is about the collusion between the managers and the independent directors. Demsetz(1983) holds the view that many managers have the right to choose and punish the independent directors, therefore it is easy for the independent directors under pressure to conspire with the managers of the company. Later, the economists represented by Laffont and Tirole using game theory and incomplete contract theory, put forward two kinds of the internal collusion of organizations, which involves the collusion between the regulator and the deputy. They believe that the regulator is driven by economic interests and will conspire with the deputy. This provides the theoretical basis for the possibility of the collusion between the managers and the independent directors.

Since there may be a collusion between managers and independent directors, we can not help asking this question: what will affect the happening of collusion and how can we break this collusion? Fama and Jensen (1983) believes that because of the deputy concerning their reputation in the labor market, the market mechanism itself can solve the moral hazard problem of asymmetric information. That is to say, a highly developed market reputation can suppress the happening of the collusion between managers and independent directors. Of course, the scholars in our country also use the game theory to study the factors that affect the collusion between managers and independent directors (Xu Min,Fu Dahong 2004; He Wentao, Huang Ying 2006). This provides a new way to study this issue. Xin Qingquan and Huang Manli (2003)thought that the supervisionand punishment mechanism from China Securities Regulatory Commission and the stock exchanges play a more important role in suppressing the happening of the collusion. But looking at previous research literature, there is little literature to introduce the third party, namely government regulator into game analysis. Therefore, based on the conspiracy theories(Laffont, Martimort 2000), the paper will construct the game model with three parts, including government regulators, managers, and independent directors in order to better reveal the internal mechanism of the happening of the collusion and provide a design thinking on how to avoid the happening of the collusion, and then provide the decision-making basis for government regulators to deal with the problem scientifically and develop a sound and reasonable regulatory system.

\section{The Motive Analysis of the Collusion between the Operator and the Independent Director}

From the perspective of the economics, the collusion between managers and independent directors is based on the "collective rationality" and all of them aim to maximize their own interests, which lead to the coupling between the demand and the supply of the collusion. On the one hand, the demand of managers inspires the supply of the independent director. For managers, they have the best advantages in terms of the rights and the information, so they can benefit a lot from the illegal manipulation. What is more, they often promise some interests to independent directors for getting their asylum, which leads to the demand of the collusion and it is also the basement. On the other hand, independent directors may cooperate well with the operator's collusion behavior. Because they are rational man and they pursuit their interest. According to those, it shows the right holders make the choice based on the rational decision. At last, the unsound regulation system in our country also provides some conditions for the collusion.

\section{Game Analysis of Collusion}

In this paper, the game model mainly involves the government supervision department, the manager and the independent director.

\section{A. The Game Hypothesis}

1) All the game participants are rational and they aim to maximize their own interests; 
2) Managers conduct the behavior of illegal manipulation (in the condition of perfect information);

3) Independent directors master the manager's behavior (in the condition of perfect information);

4) Government regulatory department post-supervise managers' manipulation and independent directors' inaction. Post-supervision mainly focuses on unusual circumstances, checks existing problems ;

5) Managers and independent directors have two choices: collude or not ;

6) The government has two choices: supervise or not ;

7) The cost and income of the game participants can be estimated.

\section{B. Construction of the Game Model}

Suppose the probability of collusion between managers and independent directors is $\mathrm{p}$ and the opposite is $(1-\mathrm{p})$; the probability of strict government supervision is $\mathrm{q}$ and the opposite is (1-q); in the condition of government supervision, the probability of collusion being found is $r$ and the opposite is (1-r). If the collusion behavior is not only successful but not being found, the managers will get extra benefit R. Because the amount of the bribe independent directors obtain from managers is proportional to the managers' extra benefit $\mathrm{R}$, the paper assumes the bribe is aR (coefficient a represents the proportion independent directors can receive from $\mathrm{R}$ ); the paper assumes the cost of government supervision is C; the extra benefit managers get means the minority shareholder's interests damage, so when the collusion fails, the minority shareholders will lose R. Because the government represents the interests of the minority shareholders, when the government fails to find collusion, it is assumed that it will lose R; when the collusion is found, the fines from the governmen is proportional to the extra benefit $R$.The paper assumes the managers' fine is bR and the independent directors' fine is caR (b and c represent the proportion managers and independent directors being charged); At the same time, the collusion will also make the independent directors' reputation fall down, and the paper assumes it will fall down by L.Based the above analysis, we learn that different strategy combinations can lead to different income distributions, and they are as follows:

1)Managers and independent directors choose collusion. If the government takes some supervisory measures and the collusion is not found, the managers, the independent directors and the government will receive $\mathrm{R}-\mathrm{aR}, \mathrm{aR}, \mathrm{C}-\mathrm{R}$; on the contrary,they will receive -bR-aR,-caR-L,bR+caR-C.If the government takes no supervisory action, they will receive $\mathrm{R}$ $\mathrm{aR}, \mathrm{aR},-\mathrm{R}$.

2)Managers and independent directors don't choose collusion.If the government takes supervisory measures, it will receive $-\mathrm{C}$, the managers and the independent directors will receive 0;If the government takes no supervisory action, action,all they will receive 0 . The sheet 1 shows different dominant strategies and the utility matrix.
TABLE I The Utility Matrix

\begin{tabular}{|c|c|c|c|}
\hline Government & Supervi & on (q) & \\
\hline $\begin{array}{l}\text { Managers } \\
\text { and } \\
\text { independent } \\
\text { directors }\end{array}$ & $\begin{array}{l}\text { Detecting the } \\
\text { collusion (r) }\end{array}$ & $\begin{array}{l}\text { Not detecting } \\
\text { the collusion } \\
\quad(1-r)\end{array}$ & $\begin{array}{c}\text { Non-supervision } \\
(1-\mathrm{q})\end{array}$ \\
\hline Collusion (p) & $\begin{array}{c}\text { (-bR-a,-caR-L, } \\
\text { bR+caR-C) }\end{array}$ & $\begin{array}{l}(\mathrm{R}-\mathrm{aR}, \mathrm{a},-\mathrm{bR}- \\
\mathrm{R})\end{array}$ & ( R-aR,aR,-R) \\
\hline Non-collusion (1-p) & $(0,0,-\mathrm{C})$ & $(0,0,-\mathrm{C})$ & $(0,0,0)$ \\
\hline
\end{tabular}

\section{The analysis of the game}

There is not the dominant pure strategy Nash equilibrium in the game but the mixed strategy Nash equilibrium.

1) The government supervisory

If the government takes some supervisory measures, it will receive the benefits $\mathrm{U}_{1}$

$$
U_{1}=p r b R+p r c a R-p c-p R+p r R-C
$$

If government does not take some supervisory action, it will receive $\mathrm{U}_{2}$

$$
U_{2}=p(-R)+(1-p) * 0
$$

If the $\mathrm{U}_{1}$ and $\mathrm{U}_{2}$ is the same, we will get the nash equilibrium and its optimal probability $\mathrm{p}^{*}$

If $\mathrm{U} 1=\mathrm{U} 2$, namely

$$
\begin{aligned}
& p r b R+p r c a R-p c-p R+p r R-C=-p R \\
& \text { We can get } p^{*}=\frac{C}{r R(b+a c+1)}
\end{aligned}
$$

If the optimal probability is $\mathrm{p}^{*}$, this equilibrium means the managers and the independent directors will choose collusion. When $\mathrm{p}>\mathrm{p}^{*}$, the government's choice of taking some supervisory measures is optimal; when $\mathrm{p}=\mathrm{p}^{*}$, whichever the choice is optimal;when $\mathrm{p}<\mathrm{p}^{*}$, the government's choice of not taking supervisory action is optimal.

$$
\text { From } p^{*}=\frac{C}{r R(b+a c+1)} \text {, the paper finds } \mathrm{p}^{*} \text { depends }
$$

on $\mathrm{C}$ (namely the cost of the supervisory), $\mathrm{r}$ (namely the probability of the successful supervisory), $\mathrm{R}$ (namely the excess returns the manager receive), a (namely the proportion the independent directors receive ), $\mathrm{b}, \mathrm{c}$ (namely the proportion of the fines they gain) and so on. The $\mathrm{p}^{*}$ is proportional to $\mathrm{C}$ and is inversely proportional to $\mathrm{r}, \mathrm{R}, \mathrm{a}, \mathrm{b}, \mathrm{c}$. So when the managers and the independent directors make choices, they should take lots of factors into consideration. What is more, it is difficult for government to control $\mathrm{R}$, a . When other factors keep still,if the government want to make the collusion fail,it should increase $\mathrm{r}, \mathrm{b}$ and $\mathrm{c}$, and decrease $\mathrm{C}$.

\section{2) Managers} $\mathrm{U}_{3}$

When the managers choose collusion, they will receive

$$
U_{3}=q r(-b R-a R)+q(1-r)(R-a R)+(1-q)(R-a R)
$$


When the managers dose not choose collusion, they will receive $\mathrm{U}_{4}$

$$
U_{4}=0
$$

When $\mathrm{U}_{3}=\mathrm{U}_{4}$, namely

$$
q r(-b R-a R)+q(1-r)(R-a R)+(1-q)(R-a R)=0
$$

The paper gets $q_{1}^{*}=\frac{1-a}{r(b+1)}$

For the managers,the optimal choice for the government is $q_{1}^{*}$.When $\mathrm{q}>q_{1}^{*}$, the optimal choice for the managers is non-collusion; when $\mathrm{q}=q_{1}^{*}$, whichever one is the optimal choice; when $\mathrm{q}<q_{1}^{*}$, the collusion is the optimal choice.

\section{3) Independent directors}

When the independent directors choose collusion, they will receive $\mathrm{U}_{5}$

$$
U_{5}=q r(a R-c a R-L)+q(1-r) a R+(1-q) a R
$$

When the independent directors do not choose collusion, they will receive $\mathrm{U}_{6}$

$$
\begin{aligned}
& \mathrm{U}_{6}=0 \\
& \text { If } \mathrm{U}_{5}=\mathrm{U}_{6}, \text { namely } \\
& \operatorname{qr}(-c a R-L)+q(1-r) a R+(1-q) a R=0
\end{aligned}
$$$$
\text { The paper gets } q_{2}^{*}=\frac{1}{r(c+1)+\frac{L}{a R}}
$$

For the independent directors, it is the optimal choice for the government to take some supervisory measures and the probability is $q_{2}^{*}$. When $\mathrm{q}>q_{2}^{*}$, it is optimal not to take collusion; when $\mathrm{q}=q_{2}^{*}$, whichever one is the optimal choice; when $\mathrm{q}<q_{2}^{*}$, collusion is the optimal choice.

From the value of $q_{1}^{*}$ and $q_{2}^{*}$, the paper find, for the managers and the independent directors, the probability of the government supervision depends on $\mathrm{r}, \mathrm{R}, \mathrm{a}, \mathrm{b}, \mathrm{c}, \mathrm{L}$ and so on. Because the government can not control a and R, it only controls r, b, c, L, which are inversely proportional to $q_{1}^{*}$ and $q_{2}^{*}$,to increase the quality of the government supervision. Besides, the government can strengthen the punishment, namely the value of $b, c$ to suppress the collusion. Besides, the collusion may damage the independent directors' reputation namely the $\mathrm{L}$, which can also suppress the collusion.

\section{Conclusion and Suggestions}

In summary, through the game analysis, we can know that to reduce the collusive activities between the managers and the independent directors, the key is to perfect supervision mechanism, improve the quality of government regulation
" $\mathrm{r}$ ",enhance the punishment strength of the responsible person "b" and "c". Specifically, it is a must to increase the cost of collusion between the two sides, to reduce its extra profit and make the collusion activities not only unable to get revenue, but also get punishment. Besides, the estimates of the loss of independent directors" reputation " $\mathrm{L}$ " in the process of the collusion will seriously affect his decision whether to participate in collusion. So we can use the way of reputation incentive and reputation punishment to prevent collusion activities. Next, the paper will combine the related influence factors, and put forward the following suggestions for the collusion problems between managers and independent directors.

First, the government should build a reasonable and effective supervision punishment mechanism, and strengthen the punishment of the collusion. Relying on the preceding game analysis, we can find whether the managers or the independent directors participate in the collusion depends on the comparison of collusion income and punishment cost. When the collusion income is less than the punishment cost, they will give up the collusion. In China, the relevant legal documents don't involve the related responsibility the independent directors should bear. So the behavior of the independent directors lacks effective institutional constraints, which will lead to the independent directors' inaction and the collusion with the manager in some way. The government can enhance the legal liability of the independent directors by strengthening the building on the securities litigation system and the securities legal liability systems.

Second, the government should improve the supervision system, and strengthen professional ethics education. Enterprise shall establish a system with the combination of internal and external supervision system, which includes the internal audit department, the supervisory board and Government regulators (mainly the CSRC). Moral has intrinsic functions of incentive and constraint on people's behavior. So in real oversight system, you can not ignore the role of morality. It is very essential t-o build the occupation moral standards between independent directors and managers, and strengthen their self-education.

Third, the government and the company should strengthen the reputation incentive and punishment mechanisms of independent directors. According to above the game analysis, some important conclusions are obtained in the conspiring process of independent directors and managers, independent directors' prediction about its loss of reputation "L" would seriously affect the decision whether he participates in collusion or not. Therefore, reputation incentive and punishment mechanism will encourage outside independent directors to supervise the managers. In our country, the national situation makes independent directors seem keener on reputation. Besides, the higher the status and the fame of the independent general director are, the more he would pay attention to maintain their own reputation, the more difficult to be bribed. So it is necessary to motivate the reputation for independent directors. In addition, government should increase reputation punishment to some independent 
directors who seriously violate the regulation by some means, such as media exposure, litigation and so on.

Last but not least, enterprises should improve the salary system of independent directors. Game model also shows that one of the reasons for independent directors to decide to conspire with managers is the extra benefit "aR" from managers. If the company designs the compensation standard of independent directors scientifically, it will reduce the effectiveness of the extra income "aR". Besides, independent directors are also more willing to take the supervision behavior. In a word, it will be necessary to improve the treatment of the independent director no matter in pay or benefits. In practice, company also can implement stock option package of independent directors. At the same time, based on considerations of independence, this plan should pay attention to the long-term options, or it is likely to happen that the independent directors encourage the short-term behavior of managers in order to gain temporary interests.

\section{References}

[1] Demsetz.H, "The structure of ownership and the theory of the firm,'Journal of Law And Economics, 1983(26): 375- 390.

[2] Fama. Eugene.F, and Michael.C.Jensen, "Separation of ownership and control,"Journal of Law and Economics, 1983(26): 301- 325.

[3] Xin Qingquan, Huang Mangli and Yi Haoran. "The false statement of listing corporation and the supervision Punishment of independent director --the analysis based on the perspective of the independent directors,"Management World, 2013(05).

[4] Xu Min,Fu Dahong, "The game analysis on the independence of independent director," China Economist, 2004(10):123-124.

[5] He Wentao, Huang Ying, "The game analysis on the incentive and constraint mechanism of independent directors in China, "Research On Development,2006(01):104-106.

[6] Jean-Jacques. Laffont, and David. Martimort, "Mechanism design with collusion and correlation ," Econometrica, 2000 (68):309-342 . 